\title{
Processing of signals from an ion-selective electrode array by a neural network
}

\author{
M. BOS *, A BOS and W E VAN DER LINDEN \\ Unwersity of Twente, Department of Chemical Technology, PO Box 217, 7500 AE Enschede (The Netherlands)
}

(Recelved 22nd February 1989)

\begin{abstract}
Neural network software is described for processing the signals of arrays of ton-selective electrodes The performance of the software was tested in the simultaneous determination of calcium and copper(II) ions in binary mixtures of copper(II) nitrate and calcium chloride and the simultaneous determination of potassium, calcium, nitrate and chloride in mixtures of potassium and calcium chlorides and ammonium nitrate The measurements for the $\mathrm{Ca}^{2+} / \mathrm{Cu}^{2+}$ determinations were done with a pH-glass electrode and calcium and copper ion-selective electrodes, results were accurate to $\pm 8 \%$. For the $\mathrm{K}^{+} / \mathrm{Ca}^{2+} / \mathrm{NO}_{3}^{-} / \mathrm{Cl}^{-}$determinations, the measurements were made with the relevant 1on-selectıve electrodes and a glass electrode; the mean relatıve error was $\pm 6 \%$, and for the worst cases the errors did not exceed $20 \%$.
\end{abstract}

The on-line simultaneous determination of ionic concentrations by means of 1on-selective electrodes (ISEs) is currently hampered by lack of selectivity, non-Nernstian response, and the influence of the ionic strength of the medium on the relationship between the wanted concentration and the activity of the ions to which the ISEs respond. Various computer methods have been described in the literature for the processing of ISE signals that address one or more of these problems [1-3]. A recent review [4] outlines the application of sophisticated chemometric techniques like partial least squares in the calibration problem for mult1ple ISEs. This paper describes an investigation of the applicability of neural network theory to solve the aforementioned problems.

Neural network theory [5-9] extends the concept of the linear learning machine (LLM) [10], the first artificial-intelligence pattern-recognition technique introduced to analytical chemistry by Jurs, Kowalski and Isenhour in the early seventies [11-13]. Greater sophistication of the training algorithm for the LLM allowed its successful use in quantitative analysis [14]. The major problem in this approach is the handling of data sets that are not linearly separable. For such sets, only an approximate solution is found, although it can be improved by introducing quadratic and crossproduct terms of the input signals [15]. Neural networks are capable of dealing with such data sets because interactions and nonlinear behaviour are automatically taken care of [5] and therefore they should be ideally suited for the processing of the signals of an ISE array.

\section{NEURAL NETWORK ALGORITHMS}

Calculation of output results from input signals

Neural network theory has been fully explained by Rumelhart and McClelland [5]. Only a working description of the algorithms used in this work is given here. A more extensive description of the backward error-propagation algorithm is avallable [9]. 


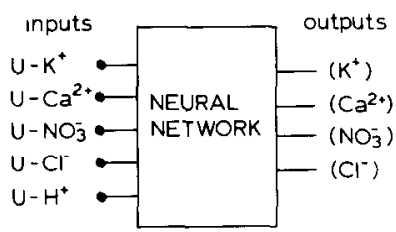

Fig. 1 Black box representation of the neural network for ISE signal processing.

Represented as a black box, the neural network recerves its input signals from the ISEs and produces the wanted concentrations at its outputs (Fig. 1). Internally, the network consists of a number of simple processing units, the neurons. These neurons receive inputs coming either from external sensors or from the outputs of other neurons. Each neuron produces one output value that can be used as an input to other neurons, or it can represent a wanted result. The way in which the neurons are interconnected is called the topology of the network (Fig. 2).

In the current literature, the processing that is done in each of the neurons is subdivided into three stages [5,9]. The first is the calculation of the input function, net, which is done here by weighted summation of its inputs:

$n e t_{t}=\sum_{J} w_{j} o_{J}$

In this equation net, is the input function of neuron $t, w_{j}$ is the weight factor associated with input $J$ to neuron $l$, and $o$ is the input $j$ to the

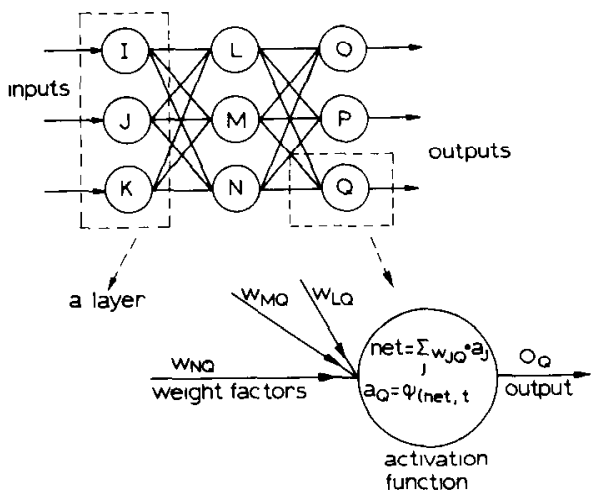

Fig 2 Topology of a neural network

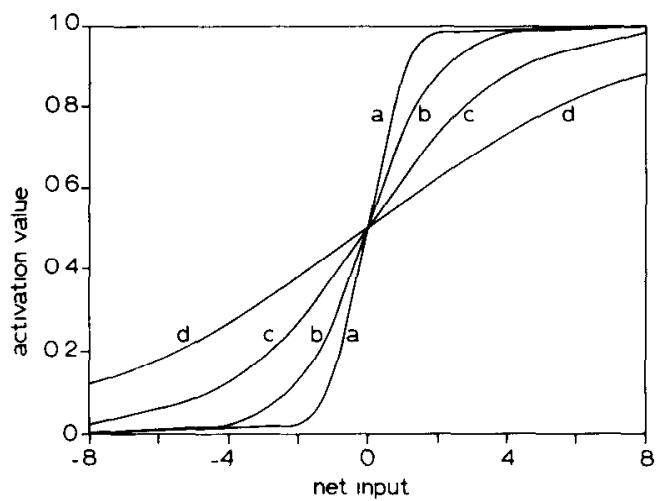

Fig. 3. Activation function for different values of the "temperature," $T$. (a) 0.5 , (b) 10 , (c) 20 ; (d) 40

neuron . The latter is either the output of a neuron of a preceding layer or an external input signal if one is dealing with the first layer.

The second step is the calculation of the activation function from the result of this input function and the preceding activation state:

$a_{t}(t)=F\left[\operatorname{net}_{l}(t), a_{\imath}(t-1)\right]$

Here $a_{t}(t)$ denotes the state of activation of neuron $i$ at time $t$ and $a_{t}(t-1)$ is its activation state at the preceding time $(t-1)$. The activation function of the neuron, $F$, is chosen here as

$a=1 /[1+\exp (-n e t / T+\theta)]$

in which $\theta$ is a bias factor and $T$ a factor that is called the "temperature". In Eqn. 3, the preceding activation is not taken into account, so that the neurons have no time-dependency here. This activation function has a sigmoidal shape; the position of the inflexion point is governed by the value of $\theta$, and the steepness by the factor $T$. Figure 3 shows a graph of this function for several $T$ values.

The third and last step of the processing done by the neurons is the calculation of the output value from the activation value. In this work, the output of a neuron is set equal to its activation value:

$o_{i}(t)=a_{1}(t)$

Equations 1-4 account for the way by which a correctly trained network calculates its output values for a given set of input measurements. 


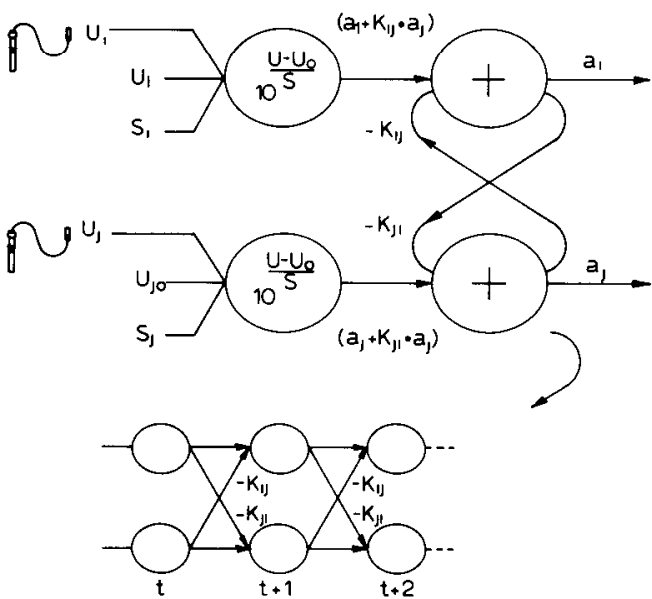

Fig. 4. Simulation of feedback in a recurrent network

\section{Training of the network}

Training of the neural network consists of finding the right combination of all weight factors $w_{\jmath}$ and the values of $\theta_{l}$ and $T_{1}$ that produces the correct output values for every input pattern (set of measurement values). This training is done with a data set consisting of sets of measurements on samples with known composition, i.e., for which the required output values are known. The algorithm that was used for this purpose is known as the generalized delta rule or backward errorpropagation rule. Its use is restricted to feed-forward layered networks. Its goal is to minimize an error function at the outputs. A pattern $p$ is

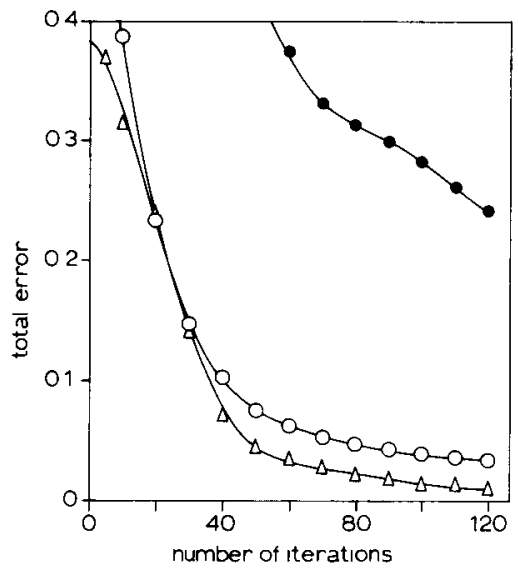

Fig. 5. Learning behaviour for various numbers of layers: $(O) 1$ layer, ( $\Delta) 2$ layers; (•) 3 layers presented to the inputs of the first layer of the network and activation values are calculated for every neuron, layer by layer, until the last layer has been reached. The error $E_{p}$ for this pattern $p$ is defined as

$E_{p}=1 / 2 \sum_{J}\left(t_{p_{J}}-o_{p_{J}}\right)^{2}$

The value $t_{p j}$ is the required output of neuron $J$ in the last layer for the pattern $p ; o_{p j}$ is the output generated by this neuron for this pattern. The total sum of square errors for all patterns is then $E_{\text {tot }}=\sum_{p} E_{p}$. To minimize this error, the weight factors of the inputs of the neurons are adjusted in proportion to the error gradient. This is done for each known pattern and repeated for the whole set of these known patterns until an acceptable total error is obtained. The equation for this adjustment is

$\Delta w_{j l}=-\epsilon \delta E_{p l} / \delta w_{\mu}$

in which the arbitrarily chosen proportıonality constant $\epsilon$ is called the learning rate.

For the last layer of neurons that produces the wanted outputs, these corrections can easily be calculated from

$\partial E_{p l} / \partial w_{j l}=\left(\partial E_{p l} / \partial o_{p l}\right)\left(\partial o_{p l} / \partial w_{j l}\right)$

Combıning this with Eqn. 5 gives

$\partial E_{p l} / \partial o_{p t}=-\left(t_{p t}-o_{p t}\right)$

The last term at the right hand side of Eqn. 6 is calculated from the activation function (Eqn. 3). Equation 4 can be left out because $o_{t}=a_{t}$ is used here. Thus

$\partial o_{\imath} / \partial$ net $t_{t}=o_{\imath}\left(1-o_{t}\right) 1 / T$

From Eqn. 1, it follows that

$\partial n t_{\imath} / \partial w_{j t}=o$,

in which $o$, is the output of neuron $J$ of the precedıng layer.

For the correction of the temperature factor, the following derivative is used:

$\partial o_{l} / \partial T=o_{l}\left(1-o_{\imath}\right)(1 / T) \ln \left[\left(1-o_{\imath}\right) / o_{t}\right]$

In the generalized delta rule, the adjustment of the weight vectors is governed by a term delta:

$\Delta w_{\jmath l}=\epsilon \operatorname{delta}_{p \imath} o_{p \jmath}$ 
TABLE 1

Measurements with $\mathrm{Cu}^{2+} / \mathrm{Ca}^{2+}$ ISEs

\begin{tabular}{|c|c|c|c|c|c|c|}
\hline Sample & $\begin{array}{l}{\left[\mathrm{Cu}^{2+}\right]} \\
\left(\mathrm{mmol} \mathrm{l^{-1 }}\right)\end{array}$ & $\begin{array}{l}{\left[\mathrm{Ca}^{2+}\right]} \\
\left(\mathrm{mmol}^{-1}\right)\end{array}$ & $\begin{array}{l}\text { Temp } \\
\left({ }^{\circ} \mathrm{C}\right)\end{array}$ & $\begin{array}{l}\text { Cu-ISE } \\
(\mathrm{mV})\end{array}$ & $\begin{array}{l}\text { Ca-ISE } \\
(\mathrm{mV})\end{array}$ & $\begin{array}{l}\text { Glass } \\
(\mathrm{mV})\end{array}$ \\
\hline 1 & 0100 & 0100 & 343 & 2260 & -21.5 & 1105 \\
\hline 2 & 0498 & 0100 & 343 & 2451 & -225 & 1168 \\
\hline 3 & 0.990 & 0.099 & 34.3 & 2530 & -235 & 1213 \\
\hline 4 & 4.988 & 0.095 & 343 & 2710 & -27.2 & 1368 \\
\hline 5 & 9.991 & 0090 & 343 & 2781 & -291 & 1454 \\
\hline 6 & 0100 & 0.500 & 346 & 224.3 & -19 & 1252 \\
\hline 7 & 0.498 & 0.498 & 34.6 & 2433 & -2.4 & 1282 \\
\hline 8 & 0990 & 0.495 & 346 & 2523 & -3.1 & 130.6 \\
\hline 9 & 4988 & 0475 & 346 & 2707 & -65 & 140.9 \\
\hline 10 & 9.991 & 0.450 & 346 & 277.8 & -8.7 & 1481 \\
\hline 11 & 0100 & 0999 & 332 & 2238 & 67 & 1390 \\
\hline 12 & 0498 & 0995 & 332 & 240.2 & 65 & 140.2 \\
\hline 13 & 0990 & 0.990 & 332 & 252.0 & 5.5 & 1409 \\
\hline 14 & 4.988 & 0.950 & 332 & 2700 & 28 & 146.6 \\
\hline 15 & 9991 & 0900 & 332 & 277.1 & 01 & 1510 \\
\hline 16 & 0100 & 5245 & 337 & 2220 & 25.9 & 1837 \\
\hline 17 & 0.498 & 5.224 & 337 & 241.0 & 25.7 & 1837 \\
\hline 18 & 0.990 & 5.198 & 337 & 249.8 & 254 & 183.5 \\
\hline 19 & 4988 & 4988 & 337 & 2697 & 234 & 182.2 \\
\hline 20 & 9991 & 4.725 & 33.7 & 276.4 & 212 & 1810 \\
\hline 21 & 0.100 & 11.089 & 345 & 2161 & 321 & 198.7 \\
\hline 22 & 0.498 & 11045 & 345 & 235.4 & 321 & 198.7 \\
\hline 23 & 0990 & 10990 & 34.5 & 2427 & 31.8 & 1989 \\
\hline 24 & 4988 & 10.546 & 345 & 2619 & 30.3 & 197.7 \\
\hline 25 & 9.991 & 9991 & 345 & 270.0 & 289 & 196.5 \\
\hline
\end{tabular}

The delta term for a neuron in the last layer which provides an output is defined as

$\operatorname{delta}_{p t}=\left(t_{p t}-o_{p t}\right) f_{i}^{\prime}\left(n e t_{p t}\right)$

With the use of Eqn. 7, this can be rewritten as

$\operatorname{delta}_{p i}=\left(t_{p l}-o_{p l}\right) o_{p l}\left(1-o_{p l}\right) / T$

For the so-called hidden neurons in the layers preceding the last layer, the target output $t_{p t}$ is unknown, so that this delta value cannot be

TABLE 2

Recognition results for some $\mathrm{Ca}^{2+} / \mathrm{Cu}^{2+}$ samples

\begin{tabular}{lllcl}
\hline Sample & $\begin{array}{l}{\left[\mathrm{Cu}^{2+}\right]} \\
\left(\mathrm{mmol} \mathrm{l}^{-1}\right)\end{array}$ & $\begin{array}{l}\text { Rel.error } \\
(\%)\end{array}$ & $\begin{array}{l}{\left[\mathrm{Ca}^{2+}\right]} \\
\left(\mathrm{mmol} \mathrm{l}^{-1}\right)\end{array}$ & $\begin{array}{l}\text { Rel.-error } \\
(\%)\end{array}$ \\
\hline 1 & 0101 & +1 & 0097 & -3 \\
2 & 0.504 & +2 & 0.091 & -1 \\
6 & 0.096 & -4 & 0.462 & -8 \\
10 & 9.306 & -7 & 0426 & -5 \\
22 & 0529 & +6 & 11128 & +1 \\
\hline
\end{tabular}

calculated. The generalized delta rule now defines this delta term for a hidden neuron as

$\operatorname{delta}_{p t}=f_{\imath}^{\prime}\left(n_{p t}\right) \sum_{k} \operatorname{delta}_{p i k} w_{\imath k}$

The error is thus propagated backwards through the layers and adjustments can be made.

From Eqns. 8 and 10, the correction factor can be calculated for the weights of the last layer of

TABLE 3

Characteristics of $\mathrm{Cu}^{2+}$ and $\mathrm{Ca}^{2+}$ ISEs calculated with the recurrent network

\begin{tabular}{|c|c|c|c|c|c|c|}
\hline \multirow[t]{2}{*}{ ISE } & \multicolumn{2}{|l|}{$U_{0}$} & \multicolumn{2}{|c|}{ Slope } & \multicolumn{2}{|l|}{$K$} \\
\hline & $N^{a}$ & $\mathrm{LG}^{\mathrm{b}}$ & $\mathrm{N}$ & LG & $\mathbf{N}$ & LG \\
\hline $\mathrm{Cu}$ & 3236 & 3306 & 257 & 263 & -0031 & -0021 \\
\hline $\mathrm{Ca}$ & 79.2 & 843 & 267 & 261 & -0.009 & -0.0015 \\
\hline
\end{tabular}

a Network, ${ }^{b}$ Linear regression 
TABLE 4

Training set for the $\mathrm{K}^{+} / \mathrm{Ca}^{2+} / \mathrm{NO}_{3}^{-} / \mathrm{Cl}^{-} / \mathrm{H}^{+}$system

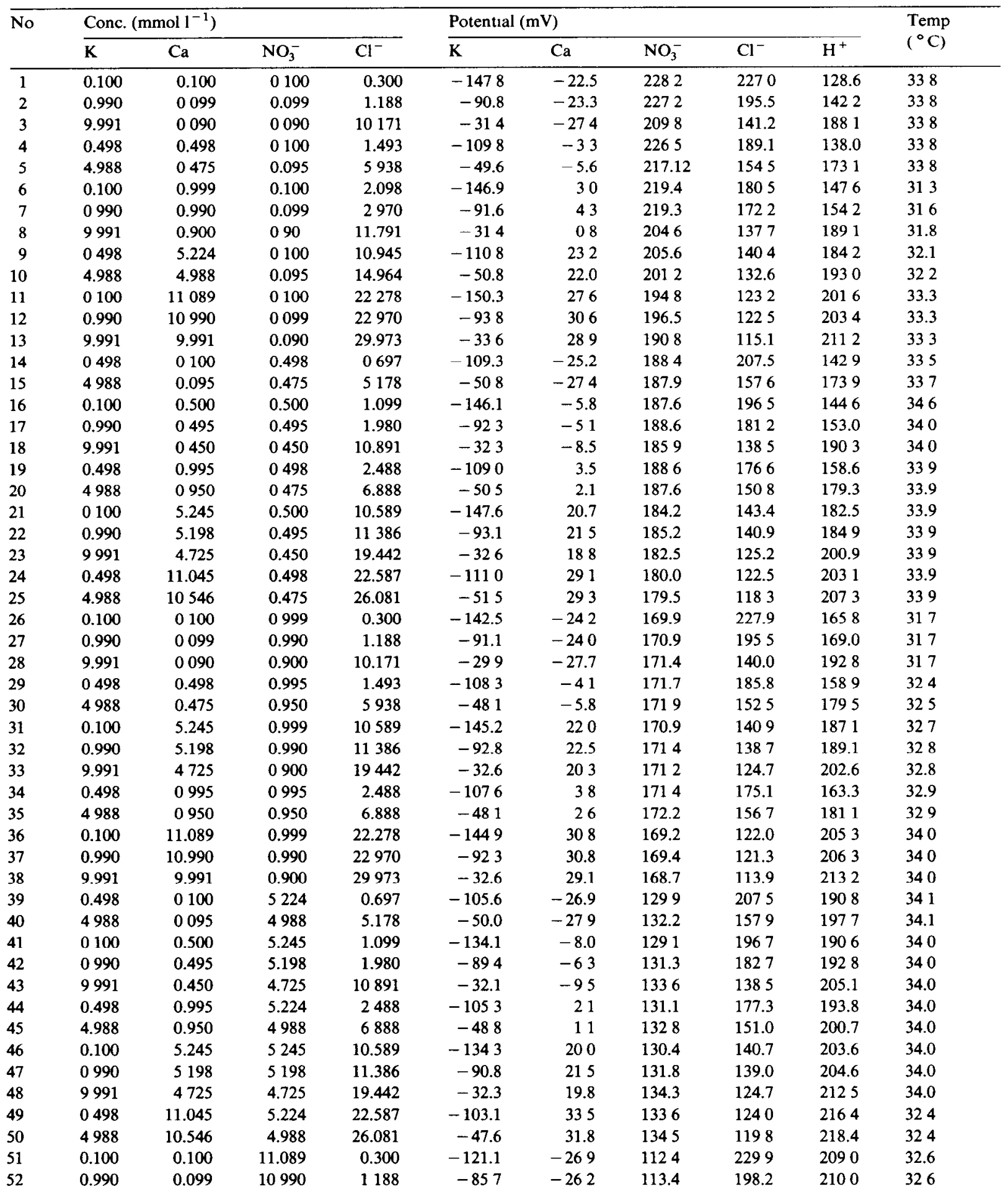


TABLE 4 (contınued)

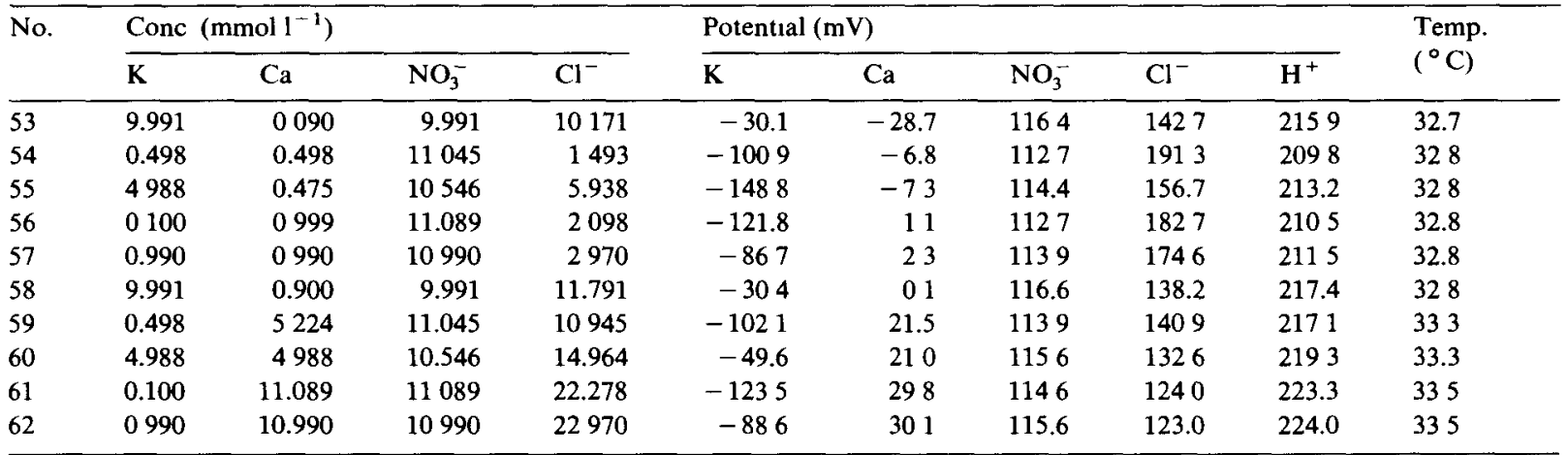

neurons. The new temperature factor is calculated from

$$
\begin{aligned}
\Delta w_{p l}= & (\epsilon / T)\left(t_{p t}-o_{p l}\right) o_{p l}\left(1-o_{p l}\right) o_{p j} \\
\Delta T_{\imath}= & \left(\epsilon_{T} / T\right)\left(t_{p l}-o_{p l}\right) o_{p l}\left(1-o_{p l}\right) \\
& \times \ln \left[\left(1-o_{p l}\right) / o_{p l}\right]
\end{aligned}
$$

For the layers which contain hidden neurons, Eqn. 11 is used together with Eqn. 8 to calculate the correction:

$\Delta w_{j l}=(\epsilon / T) o_{p l}\left(1-o_{p l}\right) o_{p J} \sum_{k} \operatorname{delta}_{p l k} w_{\iota k}$

in which the summation is over the $k$ neurons to which the neuron is connected. For the correction term of the temperature factor, the following equation is used:

$$
\begin{aligned}
\Delta T_{\imath}= & (\epsilon / T) o_{p l}\left(1-o_{p l}\right) \ln \left[\left(1-o_{p \iota}\right) / o_{p l}\right] \\
& \times \sum_{k} \operatorname{delta}_{p \iota k} w_{\iota k}
\end{aligned}
$$

For multi-layered networks, local minima can occur in $E_{t o r}$. To prevent the algorithm of being trapped in these local minima, the weight factors are corrected not only with the correction term from Eqn. 8 but also with a part of the preceding correction:

$w_{j l}(t)=w_{j l}(t-1)+\Delta w_{j l}(t)+m \Delta w_{j l}(t-1)$

where $m$ is called the momentum factor.

In the calculations, the value of the bias factor $\theta$ is taken into account as an extra input with a value of one to the neurons; $\theta$ thus becomes just another extra weight factor to be trained with the use of Eqns. 12 and 14.

\section{Simulation of feedback}

The backward error-propagation rule cannot be applied to networks in which there is feedback between the outputs of neurons to the input side of the network.

Feedback in a one-layer network can be simulated with a multi-layered network with one set of weight factors for all layers in which the sequence of the layers represents the time axis in discrete steps. Such a recurrent network simulation can be used to represent a model of the behaviour of ion-selective electrodes as given in the Nikolsky equation:

$$
U_{t}=U_{t 0}+S \log \left[a_{\imath}+\sum_{J} K_{\imath \jmath} a_{\jmath}^{n_{\imath} / n_{\jmath}}\right]
$$

where $U_{t}$ is the potential of the ISE, $U_{10}$ its standard potential, $S$ the usual slope term, $a$, the activity of the ion that is measured, $K_{1}$ the selectivity coefficient for the required ion versus the interfernng ion $J, a$, the activity of this ion $J$, and $n$, and $n$, are the charges of ion $t$ and $J$.

A schematic diagram of such a model is given in Fig. 4.

\section{EXPERIMENTAL}

\section{Chemicals and equipment}

Copper nitrate, calcium chloride, potassium chloride, ammonium chloride and ammonium 
TABLE 5

Test set for the $\mathrm{K}^{+} / \mathrm{Ca}^{2+} / \mathrm{NO}_{3}^{-} / \mathrm{Cl}^{-} / \mathrm{H}^{+}$system

\begin{tabular}{|c|c|c|c|c|c|c|c|c|c|c|}
\hline \multirow[t]{2}{*}{ No. } & \multicolumn{4}{|c|}{ Conc. $\left(\mathrm{mmol} \mathrm{l}^{-1}\right)$} & \multicolumn{5}{|c|}{ Potential (mV) } & \multirow{2}{*}{$\begin{array}{l}\text { Temp } \\
\left({ }^{\circ} \mathrm{C}\right)\end{array}$} \\
\hline & $\mathbf{K}$ & $\mathrm{Ca}$ & $\mathrm{NO}_{3}^{-}$ & $\mathrm{Cl}^{-}$ & $\mathrm{K}$ & $\mathrm{Ca}$ & $\mathrm{NO}_{3}^{-}$ & $\mathrm{Cl}^{-}$ & $\mathrm{H}^{+}$ & \\
\hline 1 & 0498 & 0100 & 0.100 & 0.697 & -107.8 & -22.3 & 2279 & 2088 & 135.3 & 33.8 \\
\hline 2 & 4988 & 0095 & 0.095 & 5.178 & -48.8 & -25.0 & 217.9 & 158.9 & 171.7 & 338 \\
\hline 3 & 0.100 & 0500 & 0.100 & 1.099 & -148.1 & -24 & 2279 & 1982 & 132.6 & 338 \\
\hline 4 & 0990 & 0495 & 0.099 & 1980 & -921 & -3.8 & 2252 & 1822 & 144.6 & 338 \\
\hline 5 & 9.991 & 0450 & 0090 & 10.891 & -316 & -7.8 & 209.0 & 1385 & 1889 & 338 \\
\hline 6 & 0.498 & 0995 & 0100 & 2488 & -108.8 & 4.3 & 219.8 & 1766 & 150.8 & 315 \\
\hline 7 & 4.988 & 0.950 & 0095 & 6888 & -493 & 2.6 & 212.0 & 151.5 & 1753 & 31.7 \\
\hline 8 & 0.100 & 5.245 & 0100 & 10589 & -1513 & 215 & 203.6 & 141.4 & 1830 & 320 \\
\hline 9 & 0.990 & 5.198 & 0.099 & 11386 & -921 & 23.2 & 205.6 & 139.5 & 1852 & 32.2 \\
\hline 10 & 9.991 & 4.725 & 0.090 & 19.442 & -323 & 210 & 1965 & 125.7 & 2007 & 32.3 \\
\hline 11 & 0.498 & 11.045 & 0.100 & 22.587 & -1110 & 308 & 1965 & 1230 & 2026 & 333 \\
\hline 12 & 4.988 & 10546 & 0.095 & 26.081 & -515 & 301 & 1908 & 1151 & 2112 & 33.3 \\
\hline 13 & 0100 & 0100 & 0500 & 0.300 & -148.6 & -279 & 1859 & 2272 & 138.0 & 335 \\
\hline 14 & 0.990 & 0.099 & 0.495 & 1.188 & -91.6 & -250 & 1891 & 1943 & 148.3 & 336 \\
\hline 15 & 9.991 & 0.090 & 0.450 & 10.171 & -32.1 & -29.1 & 185.9 & 1402 & 188.9 & 337 \\
\hline 16 & 0.498 & 0.498 & 0.498 & 1.493 & -109.5 & -5.3 & 188.1 & 188.4 & 1483 & 340 \\
\hline 17 & 4.988 & 0.475 & 0.475 & 5.938 & -50.0 & -6.5 & 187.4 & 1542 & 175.8 & 340 \\
\hline 18 & 0.100 & 0.999 & 0500 & 2098 & -1464 & 3.0 & 188.1 & 180.5 & 155.7 & 33.9 \\
\hline 19 & 0.990 & 0.990 & 0495 & 2970 & -918 & 38 & 189.1 & 172.2 & 1621 & 33.9 \\
\hline 20 & 9991 & 0.900 & 0450 & 11791 & -321 & 03 & 185.9 & 136.5 & 1921 & 33.9 \\
\hline 21 & 0.498 & 5.224 & 0.498 & 10945 & -1103 & 21.0 & 185.4 & 142.4 & 1837 & 33.9 \\
\hline 22 & 4988 & 4.988 & 0475 & 14964 & -51.3 & 19.8 & 183.9 & 132.6 & 193.0 & 33.9 \\
\hline 23 & 0.100 & 11.089 & 0.500 & 22.278 & -146.9 & 27.9 & 179.0 & 122.7 & 202.1 & 33.9 \\
\hline 24 & 0.990 & 10.990 & 0.495 & 22.970 & -94.0 & 30.6 & 180.5 & 122.0 & 203.1 & 33.9 \\
\hline 25 & 9.991 & 9991 & 0.450 & 29.973 & -33.3 & 28.4 & 1785 & 1146 & 211.5 & 339 \\
\hline 26 & 0.498 & 0.100 & 0995 & 0.697 & -108.5 & -24.0 & 1708 & 2085 & 167.0 & 317 \\
\hline 27 & 4.988 & 0.095 & 0.950 & 5.178 & -47.3 & -25.7 & 171.7 & 1576 & 182.0 & 317 \\
\hline 28 & 0100 & 0.500 & 0.999 & 1.099 & -1429 & -3.8 & 171.4 & 1957 & 1564 & 324 \\
\hline 29 & 0990 & 0.495 & 0.990 & 1980 & 908 & 4.3 & 171.9 & 1803 & 1618 & 324 \\
\hline 30 & 9991 & 0.450 & 0.900 & 10.891 & -30.4 & -7.5 & 171.9 & 137.5 & 1923 & 32.5 \\
\hline 31 & 0.498 & 5224 & 0.995 & 10.945 & -1098 & 227 & 171.7 & 140.0 & 188.1 & 32.7 \\
\hline 32 & 4.988 & 4988 & 0.950 & 14.964 & -50.3 & 217 & 171.4 & 131.6 & 1957 & 32.8 \\
\hline 33 & 0.100 & 0999 & 0.999 & 2.098 & -143.9 & 30 & 171.2 & 180.0 & 160.8 & 32.9 \\
\hline 34 & 0.990 & 0.990 & 0.990 & 2.970 & -89.9 & 35 & 172.2 & 170.4 & 166.3 & 32.9 \\
\hline 35 & 9.991 & 0.900 & 0.900 & 11791 & -30.4 & 1.3 & 172.2 & 136.0 & 193.8 & 32.9 \\
\hline 36 & 0.498 & 11045 & 0.995 & 22.587 & -109.8 & 31.1 & 169.4 & 121.8 & 205.8 & 34.0 \\
\hline 37 & 4.988 & 10.546 & 0.950 & 26.081 & -50.8 & 30.3 & 1692 & 117.6 & 209.5 & 34.0 \\
\hline 38 & 0.100 & 0.100 & 5.245 & 0.300 & -134.1 & -28.4 & 1294 & 2277 & 189.8 & 341 \\
\hline 39 & 0.990 & 0.099 & 5198 & 1188 & -89.9 & -267 & 1306 & 194.3 & 1916 & 34.1 \\
\hline 40 & 9991 & 0.090 & 4.725 & 10171 & -31.9 & -29.1 & 1336 & 139.7 & 204.3 & 341 \\
\hline 41 & 0.498 & 0498 & 5224 & 1493 & -105.1 & -6.5 & 130.6 & 189.4 & 1918 & 34.0 \\
\hline 42 & 4.988 & 0.475 & 4.988 & 5.938 & -49.3 & -7.5 & 1326 & 154.5 & 199.2 & 340 \\
\hline 43 & 0100 & 0.999 & 5245 & 2.098 & -133.4 & 0.3 & 1296 & 181.0 & 192.3 & 340 \\
\hline 44 & 0990 & 0.990 & 5.198 & 2.970 & -1899 & 2.1 & 131.3 & 1729 & 194.8 & 340 \\
\hline 45 & 9991 & 0.900 & 4.725 & 11.791 & -316 & -0.4 & 134.1 & 1368 & 206.3 & 340 \\
\hline 46 & 0.498 & 5.224 & 5.224 & 10.945 & -1061 & 21.2 & 131.1 & 1397 & 204.1 & 34.0 \\
\hline 47 & 4.988 & 4988 & 4.988 & 14.964 & -500 & 210 & 132.8 & 1316 & 208.5 & 340 \\
\hline 48 & 0.100 & 11089 & 5.245 & 22.278 & -131.4 & 323 & 133.1 & 1250 & 2159 & 32.4 \\
\hline 49 & 0.990 & 10.990 & 5.198 & 22.970 & -87.4 & 325 & 133.8 & 123.5 & 2164 & 32.4 \\
\hline 50 & 9.991 & 9.991 & 4723 & 29973 & -30.6 & 308 & 135.3 & 115.9 & 2206 & 324 \\
\hline 51 & 0.498 & 0.100 & 11.045 & 0.697 & -99.7 & -260 & 112.9 & 211.2 & 2098 & 32.6 \\
\hline 52 & 4.988 & 0.095 & 10.546 & 5.178 & -47.6 & -274 & 1146 & 1604 & 212.7 & 327 \\
\hline
\end{tabular}


TABLE 5 (contınued)

\begin{tabular}{|c|c|c|c|c|c|c|c|c|c|c|}
\hline \multirow[t]{2}{*}{ No } & \multicolumn{4}{|c|}{ Conc $\left(\mathrm{mmol} \mathrm{l}^{-1}\right)$} & \multicolumn{5}{|c|}{ Potential (mV) } & \multirow{2}{*}{$\begin{array}{l}\text { Temp } \\
\left({ }^{\circ} \mathrm{C}\right)\end{array}$} \\
\hline & $\mathbf{K}$ & $\mathrm{Ca}$ & $\mathrm{NO}_{3}^{-}$ & $\mathrm{Cl}^{-}$ & $\mathrm{K}$ & $\mathrm{Ca}$ & $\mathrm{NO}_{3}^{-}$ & $\mathrm{Cl}^{-}$ & $\mathrm{H}^{+}$ & \\
\hline 53 & 0100 & 0500 & 11.089 & 1.099 & -122.5 & -7.3 & 111.9 & 1982 & 2093 & 328 \\
\hline 54 & 0990 & 0495 & 10990 & 1.980 & -186.4 & -6.3 & 113.4 & 184.2 & 2105 & 328 \\
\hline 55 & 9.991 & 0450 & 9991 & 10891 & -306 & -8.5 & 115.9 & 1402 & 2161 & 32.8 \\
\hline 56 & 0.498 & 0.995 & 11.045 & 2488 & -1004 & 23 & 113.2 & 1788 & 2110 & 328 \\
\hline 57 & 4988 & 0950 & 10.546 & 6888 & -478 & 13 & 114.9 & 1527 & 214.2 & 328 \\
\hline 58 & 0100 & 5245 & 11.089 & 10.589 & -1233 & 212 & 112.9 & 1419 & 2166 & 33.3 \\
\hline 59 & 0990 & 5198 & 10990 & 11386 & -884 & 217 & 1144 & 140.0 & 2174 & 333 \\
\hline 60 & 9991 & 4725 & 9991 & 19442 & -319 & 20.0 & 117.1 & 1259 & 2218 & 333 \\
\hline 61 & 0.498 & 11.045 & 11045 & 22587 & -1021 & 301 & 1151 & 1232 & 2235 & 335 \\
\hline 62 & 4988 & 10.546 & 10546 & 26.081 & -500 & 296 & 1166 & 1198 & 2252 & 335 \\
\hline
\end{tabular}

nitrate were used as received (Merck, p.a.). All solutions were prepared with deionized water that had been filtered through M1llipore Q2 filters.

The following ISEs were used: for copper(II), Metrohm 6.0502.140; for calcium(II), Metrohm 6.0504.100; for chloride, Orion 94-17A; for potassium(I), Ingold 15.730.90; and for nitrate, Metrohm 6.0504.120; a combined pH-glass/reference electrode (Metrohm) was also used. Its reference electrode served for all the ISEs.

The potentials were measured with a homemade, computer-controlled, multiplexing instrument with an input impedance greater than $1 \mathrm{G} \Omega$. This high impedance was obtained with the use of an 1solating amplifier (type CA3130) for each channel. A 16-channel analog multiplexer was used to feed a selected input to an amplifier. The amplified signal was then converted to digital form by a 12-bit ADC (type AD574). This instrument was calibrated with a Knick calibration voltage source. The results indicated an accuracy of the electrode voltage readings of $\pm 0.2 \mathrm{mV}$.

Noise in the potential readings was reduced by integration and averaging of the signals over a period of $1 \mathrm{~s}$ by computer control of the instrument.

\section{Procedures}

Samples were prepared by adding calculated amounts of stock solutions of the compounds from a burette to the measuring vessel which contained $40 \mathrm{ml}$ of distilled water. The stock solutions were standardızed titrumetrically (with a relative error of $<0.3 \%$ ). The electrodes were rinsed with distilled water before use, wiped dry and then introduced into the sample. Electrode readings were taken after the temperature of the solution became stable $\left( \pm 0.2^{\circ} \mathrm{C}\right)$. During the measurements, the solution was stirred magnetically.

The software provided the following functions: dimensioning of the network and specification of the number of inputs and outputs, setting of the learning rate, the moment and the temperature adjustment and choice between adjustments for every pattern separately or for the whole training set after summation. Several options allowed the operator to store temporary results, display weights, temperatures, delta terms, activation values and concentration values calculated by the network for specific input patterns. The program is written in Pascal and runs on any MS/DOS machine.

\section{RESULTS AND DISCUSSION}

The $\mathrm{Cu}^{2+} / \mathrm{Ca}^{2+}$ system

Table 1 shows the measured data for the $\mathrm{Cu}^{2+} / \mathrm{Ca}^{2+}$ system. It includes the readings for the glass electrode. Although this signal is not directly related to the calcium and copper ion concentrations, it is nevertheless taken into account because this signal will certainly be influenced indirectly by the composition of the sample. The data are preprocessed before entering the training procedure of the network by centering the 
inputs around a mean value of 0.5 and a span of 0.25 , whereas the loganthms of the concentrations are used as the output values.

Networks with dimensions $1 \times 5,2 \times 5$ and $3 \times$ 5 were trained with this data set. As can be seen from Fig. 5, the two-layer network performs better than the network with only one layer of neurons, whereas the trainıng of the three-layer network needs much more iterations. The performance of the two-layer network is given in Table 2 which shows that the errors are in the range that is normal for ISE measurements.

The data set from Table 1 was used with the recurrent network software to determine the characteristics of the $\mathrm{Ca}^{2+}$ and $\mathrm{Cu}^{2+}$ ISEs. Table 3 shows a comparison of these characteristics evaluated by the recurrent network software and by linear regression from the Nikolsky equation. As the results of the network were found with the use of all the binary mixtures, they can be considered as more realistic.

The $\mathrm{K}^{+} / \mathrm{Ca}^{2+} / \mathrm{NO}_{3}^{-} / \mathrm{Cl}^{-} / \mathrm{H}^{+}$system

For this system, the complete set of data was divided into a training set (Table 4) and a set to evaluate the predictive performance of the trained network (Table 5).

Test runs with various sizes of network again showed that a two-layer network performs satisfactorily (Table 6). The minimum number of neurons needed per layer in this situation was found to be seven. Table 7 shows the worst-case results for the predicted concentrations.

The training calculations take a lot of computer time; generally about 10000 iterations were needed to obtain the results of Table 6 . This takes from 24

\section{TABLE 6}

Mean prediction errors for the $\mathrm{K}^{+} / \mathrm{Ca}^{2+} / \mathrm{NO}_{3}^{-} / \mathrm{Cl}^{-} / \mathrm{H}^{+}$system with various sizes of network

\begin{tabular}{llllll}
\hline Layers & \multicolumn{6}{l}{ Error (\%) for different wldths } \\
\cline { 2 - 6 } & 4 & 5 & 6 & 7 & 10 \\
\hline 1 & 13.8 & & - & - & - \\
2 & 166 & 8.2 & 74 & 5.6 & 56 \\
3 & 83 & 7.7 & 6.5 & 58 & 4.4 \\
\hline
\end{tabular}

TABLE 7

Worst-case prediction errors for the $\mathrm{K}^{+} / \mathrm{Ca}^{2+} / \mathrm{NO}_{3}^{-} / \mathrm{Cl}^{-} / \mathrm{H}^{+}$ system with the $7 \times 2$ network

\begin{tabular}{lrrrr}
\hline Sample & \multicolumn{3}{l}{ Error (\%) } & \\
\cline { 2 - 5 } & $\mathrm{K}$ & $\mathrm{Ca}$ & $\mathrm{NO}_{3}^{-}$ & $\mathrm{Cl}^{-}$ \\
\hline 5 & 0 & -8 & -19 & +7 \\
11 & +1 & +1 & -16 & +3 \\
12 & +13 & -1 & -11 & +2 \\
22 & +1 & +11 & +8 & +2 \\
23 & +3 & +12 & -5 & -1 \\
27 & +18 & +5 & +6 & 0 \\
28 & +14 & +11 & -12 & +5 \\
34 & +13 & +2 & -7 & +5 \\
43 & +14 & +6 & +7 & 0 \\
47 & +8 & 0 & +15 & +7 \\
49 & +26 & +4 & +3 & -2 \\
52 & +16 & +3 & +7 & +3 \\
\hline
\end{tabular}

to $48 \mathrm{~h}$ on an 8-Mc machine equipped with a 8087 mathematical coprocessor.

\section{REFERENCES}

1 A.F Isbell, R.L Pecsok, R.H Davies and J H Purnell, Anal. Chem., 45 (1973) 2363

2 J W Frazer, D.J. Balaban, H.R Brand, G A Robinson and S.M Lanning, Anal. Chem, 55 (1983) 855.

3 R. Jain and J S Schultz, Anal Chem, 56 (1984) 141

$4 \mathrm{M}$ Otto and J D R. Thomas, Ion-Selective Electrode Rev., 8 (1986) 55

5 D E Rumelhart and J L. McClelland, Parallel Distributed Processing, Vols 1 and 2, MIT Press, Bradford, 1986.

6 R.P Lippmann, IEEE ASSM Magazıne, April (1987) 4

7 P.D Wasserman and T Schwarz, IEEE Expert, Winter (1987) 10; Spring (1988) 10.

$8 \mathrm{~T}$ Kohonen, Self-Organization and Associative Memory, Sprınger, Berlın, 2nd edn, 1988

9 W P. Jones, Back-Propagation, Byte, October (1987) 155.

10 N J Nilsson, Learnıng Machınes, McGraw-Hıll, New York, 1965

11 P C Jurs and T.L Isenhour, Chemical Application of Pattern Recognition, Wiley, New York, 1975

$12 \mathrm{C} \mathrm{L}$ Wilkıns and T.L Isenhour, Anal. Chem, 47 (1975) 1849

13 T.L Isenhour, B R. Kowalskı and PC Jurs, CRC Crit Rev Anal. Chem, (1974) 1

14 M. Bos and G Jasınk, Anal. Chım Acta, 103 (1978) 151

15 M Bos, Anal. Chım Acta, 166 (1984) 261 